Journal of Mathematics and Statistics 4 (4): 199-200, 2008

ISSN 1549-3644

(C) 2008 Science Publications

\title{
Characterization of Chain as a Regular Semi Group
}

\author{
${ }^{1}$ R. Kehinde, and ${ }^{2}$ S.O. Makanjuola \\ ${ }^{1}$ Department of Mathematics and Statistics, Bowen University \\ P.M.B. 284, Iwo, Osun State, Nigeria \\ ${ }^{2}$ Department of Mathematics, University of Ilorin \\ P.M.B. 1515, Ilorin, Kwara State, Nigeria
}

\begin{abstract}
Problem Statement: There are some special classes of semi group namely: regular and eventually regular, abundant, orthodox, quasi-adequate. The objective of this study were to: (i) Define a new class of semi group on a Poset and give related examples (ii) Study and establish conditions that characterized Chain as a regular semi group. Approach: Tests of some of characteristics of semi group like associativity, commutativity, and regular semi group were carried out on this new class. Results: Conditions were obtained that showed it is associative and regular. Conclusion: Hence the results suggest that since Chain is regular, there are many other things we can still do this with class of semi group such as: (i) Whether one can characterize all the Green's equivalences and their starred analogues (ii) Whether one can characterize all the congruencies of the given semi group (iii) Whether one characterize all the subsemigroups of the given semi group.
\end{abstract}

Key words: Chain, binary operation, omega, partially ordered, regular semi group, total order, bicyclic

\section{INTRODUCTION}

$\mathrm{In}^{[2,3]}$, Semi group was established as a non-empty set $\mathrm{S}$ with binary operation * such that $\mathrm{S}$ is associative on $*$ that is, for all $a, b, c \in S, a *(b * c)=(a * b) * c$. If there exist an element 1 of $\mathrm{S}$ such that for every $\mathrm{a} \in \mathrm{S}, \mathrm{a}^{*} 1=$ $1 * \mathrm{a}=\mathrm{a}$. We say that 1 is an identity element of $\mathrm{S}$ and that $\mathrm{S}$ is a semi group with identity. If $\left(\mathrm{S},{ }^{*}\right)$ has an additional property that $(\forall \mathrm{a}, \mathrm{b} \in \mathrm{S}) \mathrm{ab}=\mathrm{ba}$, we say that, it is a commutative semi group.

$\mathrm{In}^{[6]}$, Dilworth discussed a partially ordered set (Poset) as a set with binary relation $\leq$ such that:

- $\quad \mathrm{a} \leq \mathrm{a} \forall \mathrm{a} \in \mathrm{S}$ (reflexivity)

- If $a \leq b$ and $b \leq c$ then $a \leq c \quad \forall a, b, c \in S$ (transitivity)

- If $\mathrm{a} \leq \mathrm{b}$ and $\mathrm{b} \leq \mathrm{a}$ then $\mathrm{a}=\mathrm{b} \quad \forall \mathrm{a}, \mathrm{b} \in \mathrm{S} \quad$ (ant symmetry)

If for any $\mathrm{a}$ and $\mathrm{b}$ in $\mathrm{S}$, either $\mathrm{a} \leq \mathrm{b}$ or $\mathrm{b} \leq \mathrm{a}$, then the partial order is called a total order or a linear order.

Therefore if a subset of $\mathrm{S}$ is totally ordered, it is called a Chain i.e., a partially ordered set in which any two elements are comparable.
If $S$ is a semi group, the element $a \in S$ is said to be regular if there exist $b \in S$ such that $a b a=a^{[5]}$.

Bicyclic semi group: A semi group $\mathrm{B}=\mathrm{N} \times \mathrm{N}$ where $\mathrm{N}$ is the set of non-negative integers and $(\mathrm{m}, \mathrm{n})(\mathrm{p}, \mathrm{q})=(\mathrm{m}-\mathrm{n}+\mathrm{t}, \mathrm{q}-\mathrm{p}+\mathrm{t})$ where $\{\mathrm{t}=\max (\mathrm{n}, \mathrm{p})\}$ is a Bicyclic semi group. $\mathrm{E}(\mathrm{B})=$ the set of idempotent of $\mathrm{B}$ defined as $E(S)=[(m, m) \in B: m \in N\}$. These have played a very important role in the study of Chain as a semi group. See for example ${ }^{[4,7] \text {. }}$

Here we know that $(1,1)>(2,2)>(3,3)>(4,4)>(5,5)$ $>\ldots$ is an omega semi group as in $^{[4]}$ because the set of idempotent elements is totally ordered, that is a Chain.

Sequences: The sequences $( \pm 2, \pm 4, \pm 8, \pm 16, \pm 32, \pm 64$, $\pm \ldots)$ and $( \pm 5, \pm 10, \pm 20, \pm 40, \pm 80, \pm 160, \pm \ldots$.$) under$ $(\mathrm{E}, /)$, is another example of a Chain ${ }^{[1]}$.

\section{MATERIALS AND METHODS}

In this study, with the above related examples, we carry out some tests by studying the nature of this semi group. Conditions were established under which Chain is a regular semi group. We later generalized a formula based on the condition.

Corresponding Author: R. Kehinde, Department of Mathematics and Statistics, Bowen University, P.M.B. 284, Iwo, Osun State, Nigeria 


\section{RESULTS}

The examples above will be considered with the following results:

Theorem 1: Let $\mathrm{P}$ be a Poset (finite or infinite) and let $\mathrm{S}$ be the direct product of $\mathrm{P}$ with $\mathrm{P}$. Define $\mathrm{a}$ multiplication on $\mathrm{S}$ by $(\mathrm{m}, \mathrm{n})^{*}(\mathrm{p}, \mathrm{q})=(\mathrm{m}, \mathrm{q})$ if $\mathrm{n}$ and $\mathrm{p}$ are comparable in $\mathrm{P}$, otherwise the product is zero. Let $\mathrm{S}=\mathrm{E}(\mathrm{S})$ and define a multiplication on $\mathrm{S}$ by $\{(\mathrm{m}, \mathrm{m}),(\mathrm{n}, \mathrm{n})\}^{*}\{(\mathrm{p}, \mathrm{p}),(\mathrm{q}, \mathrm{q})\}=\{(\mathrm{m}, \mathrm{m}),(\mathrm{q}, \mathrm{q})\}$ where $\mathrm{E}(\mathrm{B})$ $=\{(\mathrm{m}, \mathrm{m}) \in \mathrm{B}: \mathrm{m} \in \mathrm{N}\}$ then:

- $\quad\{(\mathrm{m}, \mathrm{m}),(\mathrm{n}, \mathrm{n}) *(\mathrm{p}, \mathrm{p}),(\mathrm{q}, \mathrm{q})\} *\{(\mathrm{r}, \mathrm{r}),(\mathrm{s}, \mathrm{s})\}=\{(\mathrm{m}, \mathrm{m}),(\mathrm{n}, \mathrm{n}$ )$\} *\{(\mathrm{p}, \mathrm{p}),(\mathrm{q}, \mathrm{q}) *(\mathrm{r}, \mathrm{r}),(\mathrm{s}, \mathrm{s})\}$

- $\quad\{(\mathrm{m}, \mathrm{m}),(\mathrm{n}, \mathrm{n})\} *\{(\mathrm{p}, \mathrm{p}),(\mathrm{q}, \mathrm{q})\} \neq$ $\{(\mathrm{p}, \mathrm{p}),(\mathrm{q}, \mathrm{q})\} *\{(\mathrm{~m}, \mathrm{~m}),(\mathrm{n}, \mathrm{n})\}$

- $\quad\{(\mathrm{m}, \mathrm{m}),(\mathrm{n}, \mathrm{n}) *(\mathrm{p}, \mathrm{p}),(\mathrm{q}, \mathrm{q}) *(\mathrm{~m}, \mathrm{~m}),(\mathrm{n}, \mathrm{n})\}=\{(\mathrm{m}, \mathrm{m}),(\mathrm{n}, \mathrm{n}$ )$\}$

Theorem 2: Let $\mathrm{P}$ be a poset (finite or infinite) and let $\mathrm{S}$ be the direct product of $\mathrm{P}$ with $\mathrm{P}$. Define $\mathrm{a}$ multiplication on $\mathrm{S}$ by $(\mathrm{m}, \mathrm{n})^{*}(\mathrm{p}, \mathrm{q})=(\mathrm{m}, \mathrm{q})$ if $\mathrm{n}$ and $\mathrm{p}$ are comparable in $\mathrm{P}$, otherwise the product is zero. And let $S=( \pm 2, \pm 4, \pm 8, \pm 16, \pm 32, \pm 64)$ under $(\mathrm{E}, /)$, then conditions (i),(ii) and (iii) of Theorem 1 hold.

\section{DISCUSSION}

The proofs of theorem 1 and 2 above are based on the test for associativity, commutativity and regular semi group as below.

\section{For Associativity:}

$\{(\mathrm{m}, \mathrm{m}),(\mathrm{n}, \mathrm{n}) *(\mathrm{p}, \mathrm{p}),(\mathrm{q}, \mathrm{q})\} *\{(\mathrm{r}, \mathrm{r}),(\mathrm{s}, \mathrm{s})\}=\{(\mathrm{m}, \mathrm{m}),(\mathrm{n}, \mathrm{n})\} *\{$ $(\mathrm{p}, \mathrm{p}),(\mathrm{q}, \mathrm{q}) *(\mathrm{r}, \mathrm{r}),(\mathrm{s}, \mathrm{s})\}$

i.e $\{(\mathrm{m}, \mathrm{m}),(\mathrm{n}, \mathrm{n}) *(\mathrm{p}, \mathrm{p}),(\mathrm{q}, \mathrm{q})\}^{*}\{(\mathrm{r}, \mathrm{r}),(\mathrm{s}, \mathrm{s})\}$ LHS

$=\{(\mathrm{m}, \mathrm{m}),(\mathrm{q}, \mathrm{q})\}^{*}\{(\mathrm{r}, \mathrm{r}),(\mathrm{s}, \mathrm{s})\}$

$=\{(\mathrm{m}, \mathrm{m}),(\mathrm{s}, \mathrm{s})\}$

Also, $\{(\mathrm{m}, \mathrm{m}),(\mathrm{n}, \mathrm{n})\} *\{(\mathrm{p}, \mathrm{p}),(\mathrm{q}, \mathrm{q}) *(\mathrm{r}, \mathrm{r}),(\mathrm{s}, \mathrm{s})\}$ RHS

$=\{(\mathrm{m}, \mathrm{m}),(\mathrm{n}, \mathrm{n})\} *\{(\mathrm{p}, \mathrm{p}),(\mathrm{s}, \mathrm{s})\}$

$=\{(\mathrm{m}, \mathrm{m}),(\mathrm{s}, \mathrm{s})\}$

Since LHS $=$ RHS

It is associative, implies it is a semi group.

\section{For commutativity:}

$\{(\mathrm{m}, \mathrm{m}),(\mathrm{n}, \mathrm{n})\} *\{\mathrm{p}, \mathrm{p}),(\mathrm{q}, \mathrm{q})\}=\{(\mathrm{p}, \mathrm{p}),(\mathrm{q}, \mathrm{q})\} *\{(\mathrm{~m}, \mathrm{~m}),(\mathrm{n}, \mathrm{n})$

\}

i.e., $\{(m, m),(n, n)\} *\{(p, p),(q, q)\}=\{(m, m),(q, q)\}$ LHS

And $\{(\mathrm{p}, \mathrm{p}),(\mathrm{q}, \mathrm{q})\}^{*}\{(\mathrm{~m}, \mathrm{~m}),(\mathrm{n}, \mathrm{n})\}=\{(\mathrm{p}, \mathrm{p}),(\mathrm{n}, \mathrm{n})\}$ RHS
LHS $\neq$ RHS $\Rightarrow\{(m, m),(n, n)\}^{*}\{(p, p),(q, q)\} \quad \neq$ $\{(\mathrm{p}, \mathrm{p}),(\mathrm{q}, \mathrm{q})\} *\{(\mathrm{~m}, \mathrm{~m}),(\mathrm{n}, \mathrm{n})\}$

This shows that it is not a commutative semi group.

\section{For regular semi group:}

$\{(\mathrm{m}, \mathrm{m}),(\mathrm{n}, \mathrm{n}) *(\mathrm{p}, \mathrm{p}),(\mathrm{q}, \mathrm{q}) *(\mathrm{~m}, \mathrm{~m}),(\mathrm{n}, \mathrm{n})\}=\{(\mathrm{m}, \mathrm{m}),(\mathrm{n}, \mathrm{n})\}$

i.e., $\{(m, m),(n, n) *(p, p),(q, q) *(m, m),(n, n)\}$

$$
=\left\{(\mathrm{m}, \mathrm{m}),(\mathrm{q}, \mathrm{q})^{*}(\mathrm{~m}, \mathrm{~m}),(\mathrm{n}, \mathrm{n})\right\}
$$$$
=\{(\mathrm{m}, \mathrm{m}),(\mathrm{n}, \mathrm{n})\}
$$

It is a regular semi group.

In general: $\left\{\left(\mathrm{m}_{1}, \mathrm{~m}_{1}\right),\left(\mathrm{n}_{1}, \mathrm{n}_{1}\right)\right\}^{*}\left\{\left(\mathrm{~m}_{2}, \mathrm{~m}_{2}\right),\left(\mathrm{n}_{2}, \mathrm{n}_{2}\right)\right\}$

$$
=\left\{\left(\mathrm{m}_{1}, \mathrm{~m}_{1}\right),\left(\mathrm{n}_{2}, \mathrm{n}_{2}\right)\right\}
$$

\section{CONCLUSION}

Chain as a regular semi group can be applied in operating system particularly in automoto languages and in coding theory. Since it is regular, we can still go further to study whether the lattices of congruencies/subsemi groups can be described.

\section{REFERENCES}

1. Godman, A. and J.F. Talbert, 1984. Additional Mathematics for West Africa. 7th Edn., Longman Group (FE) Limited, UK., pp: 266-270. ISBN: 0582-58830-8.

2. Howie, J.M., 1976. An Introduction to Semi group Theory. Academic Press, pp: 282. ISBN: -10: 0123569508.

3. Howie, J.M., 1995. Fundamentals of Semi group Theory. Illustrated Edn., Oxford University Press, pp: 351. ISBN: 0198511949.

4. Makanjuola, S.O. and A. Umar, 1977. On a certain subsemi group of bicyclic semi group. Communicat. Algebra, 25: 509-519. DOI: 10.1080/00927879708825870

5. Petrich, M., 1973. Regular Semi groups which are Subdirect products of a band and a Semilattice of a band and a Semilattice of groups. Glasgow Math. J., 14: 27-49.

6. Tverberg, H., 1967. On Dilworth's decomposition theorem for partially ordered sets. J. Combinatorial Theory,3:305-306.

7. Yamada, M. and N. Kimura, 1958. Note on idempotent semi group 11. Proc. Japan Acad., 34: 110-112. http://www.citeulike.org/user/algorithmic/article/8 16929 